\title{
IR AND UV-VISIBLE SPECTRA OF IRON(II) PHTHALOCYANINE COMPLEXES WITH PHOSPHINE OR PHOSPHITE
}

\author{
A. Zanguina, M. Bayo-Bangoura, K. Bayo and G.V. Ouedraogo* \\ Laboratoire De Chimie De Coordination, Ufr-Sea - Universite De Ouagadougou - 03 BP 7021 \\ Ouagadougou 03, Burkina Faso
}

(Received September 10, 2001; revised February 26, 2002)

\begin{abstract}
We have prepared and studied by vibrational and electronic spectrometry of a series of ferrophthalocyanine complexes with phosphine or phosphite axial ligands $\left[\mathrm{PMe}_{3}, \mathrm{P}(\mathrm{OMe})_{3}, \mathrm{PPh}_{3}\right.$, $\mathrm{P}(\mathrm{OPh})_{3}, \mathrm{PPh}(\mathrm{OMe})_{3}$ and $\left.\mathrm{POH}(\mathrm{OEt})_{2}\right]$. With $\mathrm{PMe}_{3}, \mathrm{P}(\mathrm{OMe})_{3}$ as ligands, only hexacoordinated complexes are obtained but with $\mathrm{PPh}_{3}, \mathrm{P}(\mathrm{OPh})_{3}$ and $\mathrm{POH}(\mathrm{OEt})_{2}$ as ligands, the coordination number depends on the FePc:ligand ratio in the reaction mixture. In the ratio 1:1 the complexes thus formed are pentacoordinated and in the ratio 1:2 hexacoordinated complexes are obtained. In the electronic spectra of hexacoordinated complexes, two charge-transfer transition bands, one at $\sim 375$ $\mathrm{nm}$ and the other at $\sim 421 \mathrm{~nm}$ can be observed. We attribute the band at $375 \mathrm{~nm}$ to charge-transfer from axial ligand to macrocycle (CT $\mathrm{L}_{\mathrm{ax}} \rightarrow \mathrm{Pc}$ ) and the band at $421 \mathrm{~nm}$ to charge-transfer from metal to axial ligand $\left(\mathrm{CT} \mathrm{Fe} \rightarrow \mathrm{L}_{\mathrm{ax}}\right.$ ). In the IR spectra, the position of the $v_{\mathrm{FeN} 4}$ band is linked to the coordination number; in the spectra of pentacoordinated complexes, its frequency is almost the same as that in the FePc spectrum but in hexacoordinated complexes, it moves to high frequencies.
\end{abstract}

KEY WORDS: Iron(II) phthalocyanine complexes, Phosphine, Phosphite, Vibrational spectrometry of ferrophthalocyanine complexes, Electronic spectrometry of ferrophthalocyanine complexes

\section{INTRODUCTION}

Metallophthalocyanines [MPc] possesses a system of delocalised $\pi$-electrons. This delocalisation and the interactions of the $\pi$-electron with the central metal atom determine the redox properties of these complexes [1, 2]. These in turn led to the study of semi-conductivity, photoconductivity, photochemical reactions, photosynthetic and electrocatalytical activities, etc. [3-7]. An important theme has been to determine the influence of axial or equatorial ligands on the physico-chemical properties of the complexes [8-11]. Phthalocyaninato iron(II) is a widely investigated porphyrin-like molecule which exhibits a strong tendency to axial ligation. A former study of its adduct complexes with pyridine and substitued pyridines gave a consistent view of the axial and equatorial $\pi$-bonding in the series $[8,11]$. There is, however, very little information concerning the compounds made by the reaction of FePc with phosphine or phosphite ligands [12-14].

In this paper, we present the results of the preparation and study by vibrational and electronic spectrometry of a series of FePc complexes containing axial phosphine or phosphite ligands. The ligands which are used are $\mathrm{PMe}_{3}, \mathrm{P}(\mathrm{OMe})_{3}, \mathrm{PPh}_{3}, \mathrm{P}(\mathrm{OPh})_{3}, \mathrm{PPh}(\mathrm{OMe})_{2}$, and $\mathrm{POH}(\mathrm{OEt})_{2}$. 
Preparation of compounds

FePc. We have obtained this compound from a method developed in our Laboratory [15]. The pure product is obtained with a yield of $75 \%$.

FePcL pentacoordinated complexes. The pentacoordinated compounds were obtained by heating to $70{ }^{\circ} \mathrm{C}$, with stiring, an equimolar mixture of FePc and the ligand in DMSO; the time of reaction varies with the ligand.

$\left[\mathrm{FePc}\left\{\mathrm{POH}(\mathrm{OEt})_{2}\right\}\right]$. A mixture of FePc $(1 \mathrm{~g}, 1.760 \mathrm{mmol})$ and $\mathrm{POH}(\mathrm{OEt})_{2}(0.245 \mathrm{~g}, 1.760$ $\mathrm{mmol}$ ) in $50 \mathrm{~mL}$ of DMSO was heated $70{ }^{\circ} \mathrm{C}$ with stirring. After $3 \mathrm{~h}$ the mixture was cooled, the solid was filtered off, washed with $\mathrm{EtOH}$ and dried in vacuum over $\mathrm{P}_{2} \mathrm{O}_{5}$. The yield (R) was $70 \%$. The reaction lasts for $3 \mathrm{~h}$ for $\left[\mathrm{FePc}\left\{\mathrm{PPh}_{3}\right\}\right]$ (the yield, $\mathrm{R}$, was $73 \%$ ), 11/2 $\mathrm{h}$ for $\left[\mathrm{FePc}\left\{\mathrm{P}(\mathrm{OPh})_{3}\right\}\right]($ yield $67 \%)$ and $10 \mathrm{~h}$ for $\left[\mathrm{FePc}\left\{\mathrm{PPh}(\mathrm{OMe})_{2}\right\}\right]($ yield $75 \%)$.

FePcL $L_{2}$ hexacoordinated compounds

These compounds were obtained from the methods described in the literature $[12,13,16]$.

$\left[\mathrm{FePc}\left\{\mathrm{P}(\mathrm{OMe})_{3}\right\}_{2}\right]$. A mixture of FePc $(1 \mathrm{~g}, 1.760 \mathrm{mmol})$ and $\mathrm{P}(\mathrm{OMe})_{3}(1.5 \mathrm{~mL}, 3.521 \mathrm{mmol})$ in DMSO was heated up to $70{ }^{\circ} \mathrm{C}$ with stirring. After $1 \frac{1 / 2}{\mathrm{~h}}$ the mixture was cooled, the solid was filtered off, washed with $\mathrm{EtOH}$, then dried in vacuum over $\mathrm{P}_{2} \mathrm{O}_{5}$. The yield (R) was $62 \%$.

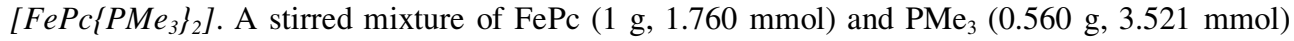
in DMSO was heated to $70{ }^{\circ} \mathrm{C}$ for $10 \mathrm{~h}$. After cooling, the solid was filtered off, washed with EtOH, then dried in vaccuum over $\mathrm{P}_{2} \mathrm{O}_{5}$. $(\mathrm{R}=57 \%)$.

$\left[\mathrm{FePc}\left\{\mathrm{PPh}_{3}\right\}_{2}\right],\left[\mathrm{FePc}\left\{\mathrm{P}(\mathrm{OPh})_{3}\right\}_{2}\right]$ and $\left[\mathrm{FePc}\left\{\mathrm{POH}(\mathrm{OEt})_{2}\right\}_{2}\right]$. These compounds were obtained in the same way as $\left[\mathrm{FePc}\left\{\mathrm{PMe}_{3}\right\}_{2}\right]$ by use of the corresponding ligand. The reaction yields were $50 \%$ for $\left[\mathrm{FePc}\left\{\mathrm{PPh}_{3}\right\}_{2}\right], 51 \%$ for $\left[\mathrm{FePc}\left\{\mathrm{P}(\mathrm{OPh})_{3}\right\}_{2}\right]$ and $67 \%$ for $\left[\mathrm{FePc}\left\{\mathrm{POH}(\mathrm{OEt})_{2}\right\}_{2}\right]$.

\section{Reagents and apparatus}

Phosphine and phosphite ligands were commercially grade (ACROS) and were used without purification.

The IR absorption spectra were obtained on a PERKIN ELMER 843 spectrometer from $\mathrm{KBr}$ discs at $1 \%$ for the $700-1600 \mathrm{~cm}^{-1}$ domain and from CsI discs at $10 \%$ for the $200-650 \mathrm{~cm}^{-1}$ domain. The UV-visible spectra were obtained on a PHILIPS S-1000 spectrometer from saturated solutions of compounds in DMSO or benzene. 
Electronic absorption spectrometry of pentacoordinated complexes

For axially substituted compounds we noticed that the nature of the reaction product between FePc and phosphine or phosphite ligands depends on the quantity of ligand which is used. With FePc:L in 1:1 ratio, these ligands with FePc form pentacoordinated complexes [FePcL] and with FePc:L in 1:2 ratio the complex formed is hexacoordinated $\left[\mathrm{FePcL}_{2}\right]$.

As far as we know, this is the first time FePc pentacoordinated compounds with phosphine or phosphite ligands have been prepared and isolated in the solid form.

The wavelengths of the bands of FePc and pentacoordinated species of FePc having phosphine or phosphite in axial position in DMSO and in benzene are grouped in Table 1 below.

Table 1. Wavelengths of noticeable bands in DMSO and in benzene (nm).

\begin{tabular}{|c|l|l|c|c|}
\hline Solvents & Compounds & $\lambda^{*}{ }_{\mathrm{Q}}$ & $\lambda_{\mathrm{S}}{ }_{\mathrm{S}}$ & $\lambda_{\mathrm{B}}{ }_{\mathrm{B}}$ \\
\hline \multirow{4}{*}{ DMSO } & $\mathrm{FePc}$ & 652 & 594 & 330 \\
\cline { 2 - 5 } & {$\left[\mathrm{FePc}\left\{\mathrm{P}(\mathrm{OPh})_{3}\right\}\right]$} & $678 ; 652$ & 590 & 320 \\
\cline { 2 - 5 } & {$\left[\mathrm{FePc}\left\{\mathrm{PPh}_{3}\right\}\right]$} & $675 ; 645$ & 587 & 327 \\
\cline { 2 - 5 } & {$\left[\mathrm{FePc}\left\{\mathrm{POH}(\mathrm{OEt})_{2}\right\}\right]$} & $675 ; 642$ & 585 & 321 \\
\hline \multirow{2}{*}{ Benzene } & $\mathrm{FePc}$ & 704 & 651 & 330 \\
\cline { 2 - 5 } & {$\left[\mathrm{FePc}\left\{\mathrm{POH}(\mathrm{OEt})_{2}\right\}\right]$} & $678 ; 651$ & - & 327 \\
\hline
\end{tabular}

${ }^{*} \mathrm{Q}=$ transition band $\pi \rightarrow \pi *, \mathrm{~B}=$ Soret band, $\mathrm{S}=$ shoulder.

The FePc spectrum in DMSO is similar to that of the literature with two main bands at 652 $\mathrm{nm}$ ( $\mathrm{Q}$ band) and at $330 \mathrm{~nm}$ (Soret band or B band). The change of solvent results changes to the relative intensity and frequency of $\mathrm{Q}$ band but the Soret band is unchanged. The $\mathrm{Q}$ band at 652 $\mathrm{nm}$ in DMSO moves to $704 \mathrm{~nm}$ in benzene with a lower relative intensity. The same phenomena have already been observed in changing from DMSO to chloronaphthalene solution [17].

For the pentacoordinated compounds, the spectra in DMSO solution present a Soret band which is almost the same as that of the FePc spectrum and a $\mathrm{Q}$ band which possesses two maxima at $645 \mathrm{~nm}$ and $676 \mathrm{~nm}$. Such a splitting of the $\mathrm{Q}$ band has been observed in the spectra of the [ $\left.\mathrm{FePc}\left(\mathrm{H}_{2} \mathrm{O}\right)\right]$ [18], [FePcPy] [19], [FePcSR] [17] and [FePcCl] [16]. This phenomenon is characteristic of FePc pendacoordinated complexes [16-19]. Some authors explain this by the molecule symmetry change from $\mathrm{D}_{4 \mathrm{~h}}$ for $\mathrm{FePc}$ to $\mathrm{C}_{4 v}$ for the pentacoordinated species. This symmetry change would leave some orbital degeneracies and result in splitting of the Q band in the spectra.

The very low solubility of the compounds in benzene made it possible for us to obtain spectra only for $\mathrm{FePc}$ and $\left[\mathrm{FePc}\left\{\mathrm{POH}(\mathrm{OEt})_{2}\right\}\right]$. The results obtained in benzene with $\left[\mathrm{FePc}\left\{\mathrm{POH}(\mathrm{OEt})_{2}\right\}\right]$ confirm those which have been obtained in DMSO. The only one difference is the disappearance in the spectrum in benzene of the shoulder at $585 \mathrm{~nm}$ in DMSO.

\section{Hexacoordinated compounds spectra}

Table 2 shows the wavelengths of the maxima of the FePc bands and of the hexacoordinated derivatives.

Table 2. Wavelengths (nm) of the noticeable bands in DMSO and in benzene.

\begin{tabular}{|c|l|l|l|c|c|c|}
\hline Solvent & Compounds & $\lambda_{\mathrm{Q}}$ & $\lambda_{\mathrm{S}}$ & $\begin{array}{c}\lambda_{\mathrm{CT}} \\
\mathrm{L}_{\mathrm{ax}} \rightarrow \mathrm{PC}\end{array}$ & $\begin{array}{c}\lambda_{\mathrm{CT}} \\
\mathrm{Fe} \rightarrow \mathrm{L}_{\mathrm{ax}}\end{array}$ & $\lambda_{\mathrm{B}}$ \\
\cline { 2 - 5 }
\end{tabular}




\begin{tabular}{|c|c|c|c|c|c|c|}
\hline \multirow{6}{*}{ Benzene } & $\mathrm{FePc}$ & 704 & 651 & - & - & 330 \\
\hline & {$\left[\mathrm{FePc}\left\{\mathrm{PMe}_{3}\right\}_{2}\right]$} & 663 & 600 & 376 & 430 & 321 \\
\hline & {$\left[\mathrm{FePc}\left\{\mathrm{P}(\mathrm{OMe})_{3}\right\}_{2}\right]$} & 660 & 600 & 375 & 434 & 324 \\
\hline & {$\left[\mathrm{FePc}\left\{\mathrm{PPh}_{3}\right\}_{2}\right]$} & 654 & 594 & - & 410 & 331 \\
\hline & {$\left[\mathrm{FePc}\left\{\mathrm{P}(\mathrm{OPh})_{3}\right\}_{2}\right]$} & 660 & 600 & - & 419 & 324 \\
\hline & {$\left[\mathrm{FePc}\left\{\mathrm{POH}(\mathrm{OEt})_{2}\right\}_{2}\right.$} & 652 & 593 & - & 412 & 327 \\
\hline \multirow{6}{*}{ DMSO } & $\mathrm{FePc}$ & 652 & 594 & - & - & 330 \\
\hline & {$\left[\mathrm{FePc}\left\{\mathrm{PMe}_{3}\right\}_{2}\right]$} & 661 & 600 & - & 382 & 328 \\
\hline & {$\left[\mathrm{FePc}\left\{\mathrm{P}(\mathrm{OMe})_{3}\right\}_{2}\right]$} & 655 & 594 & - & 410 & 330 \\
\hline & {$\left[\mathrm{FePc}\left\{\mathrm{PPh}_{3}\right\}_{2}\right]$} & 654 & 593 & - & - & 324 \\
\hline & {$\left[\mathrm{FePc}\left\{\mathrm{P}(\mathrm{OPh})_{3}\right\}_{2}\right]$} & 652 & 594 & - & - & 330 \\
\hline & {$\left[\mathrm{FePc}\left\{\mathrm{POH}(\mathrm{OEt})_{2}\right\}_{2}\right.$} & 654 & 591 & - & - & 327 \\
\hline
\end{tabular}

In general, the spectra of the hexacoordinated derivatives in benzene present additional bands which are not observed in that of FePc. Two groups can be observed: with $\mathrm{PMe}_{3}$ and $\mathrm{P}(\mathrm{OMe})_{3}$ ligands, two additional bands can be observed at about 375 and $432 \mathrm{~nm}$ and with the $\mathrm{PPh}_{3}, \mathrm{P}(\mathrm{OPh})_{3}$ and $\mathrm{POH}(\mathrm{OEt})_{2}$ ligands only one band is visible around $414 \mathrm{~nm}$ (see Table 2). Similar results have been obtained by Swaigart [13] with $\left[\mathrm{FePc}\left\{\mathrm{PBu}_{3}\right\}_{2}\right]$ and $\left[\mathrm{FePc}\left\{\mathrm{P}(\mathrm{OBu})_{3}\right\}_{2}\right]$ in toluene solution, but the author did not make any comment concerning the origin of these new bands. Works in our Laboratory on $\left[\mathrm{FePcL}_{2}\right]$ complexes with nitrogen aromatic bases such as pyridine and substituted pyridines $[8,9]$ makes it possible for us to attribute the band at $\sim 375 \mathrm{~nm}$ to a charge-transfer from the axial ligand towards the macrocycle through the central metal (CT $\mathrm{L}_{\mathrm{ax}} \rightarrow \mathrm{Pc}$ ) and the band at $\sim 421 \mathrm{~nm}$ to charge-transfer from the metal towards the axial ligand $\left(\mathrm{CT} \mathrm{Fe} \rightarrow \mathrm{L}_{\mathrm{ax}}\right)$.

The phosphine and phosphite ligands are Lewis bases with empty $\mathrm{d}-\pi$ orbitals which are likely to receive electrons through back donation. That makes us think that these ligands have properties similar to those of the substituted pyridine. It is therefore not surprising that there can exist bands of $\mathrm{CT} \mathrm{L}_{\mathrm{ax}} \rightarrow \mathrm{Pc}$ type and $\mathrm{Fe} \rightarrow \mathrm{L}_{\mathrm{ax}}$ type in the spectra of the hexacoordinated derivatives we have obtained.

The fact that the energies of these transitions are lower with the pyridine and substituted pyridine ligands than with phosphines and phosphites can be explained by the fact that in pyridine, it is the donor power that dominates while in phosphines and phosphites, there are empty orbitals which are able to accept electrons; so that, in this laters there is a coexistence of the donating and attracting powers. It is also established that the nitrogen bases such as pyridine are more susceptible to inductive effects than are phosphine and phosphite [19]. That results in the formation of pyridine bases whose field is stronger than those of phosphines and phosphites.

In DMSO solution, the $\left[\mathrm{FePc}\left\{\mathrm{PMe}_{3}\right\}_{2}\right]$ and $\left[\mathrm{FePc}\left\{\mathrm{P}(\mathrm{OMe})_{3}\right\}_{2}\right]$ spectra are the only ones which differ from that of FePc. An additional band at about $400 \mathrm{~nm}$, attributable to CT Fe $\rightarrow \mathrm{L}_{\mathrm{ax}}$ can be observed. No additional band is visible in the spectra of compounds with $\mathrm{PPh}_{3}, \mathrm{P}(\mathrm{OPh})_{3}$ and $\mathrm{POH}(\mathrm{OEt})_{2}$ ligands (see Table 2). We think that the absence of CT bands in the spectra of the compounds with these ligands can be explained by the failure of the ligands to displace DMSO from the Fe coordination sphere.

Comparison of the spectra of hexacoordinated and pentacoordinated derivatives makes it possible to observe the following:

i) The $\mathrm{Q}$ band appears in spectra of the hexacoordinated derivatives at around $652 \mathrm{~nm}$ while in spectra of the pentacoordinated derivatives, this band shows maxima at around 676 and $645 \mathrm{~nm}$. 
ii) Charge-transfer bands appear in the hexacoordinated derivatives spectra which are not observed in either the FePc spectrum or in those of the pentacoordinated derivatives.

\section{Infrared absorption spectra}

The introduction of the phosphine or phosphite ligands in the axial position of FePc is shown in the spectra by a variation of relative intensities of bands in the $1000-1600 \mathrm{~cm}^{-1}$ domain and by the appearance of new bands.

The most notable modifications appear in the $\left[\mathrm{FePc}\left\{\mathrm{P}(\mathrm{OMe})_{3}\right\}_{2}\right]$ spectrum. In the spectrum of this compound an increase of the intensities of the bands at 1490 and $1160 \mathrm{~cm}^{-1}$ can be observed while that of the band at $1330 \mathrm{~cm}^{-1}$ decreases. As the band at $1160 \mathrm{~cm}^{-1}$ is associated with the $\mathrm{C}-\mathrm{H}$ vibrations of the macrocycle, it can be assumed that the presence of the $\mathrm{CH}_{3}$ groups in the axial $\mathrm{P}(\mathrm{OMe})_{3}$ ligand leads to the increase in intensity of this band. Two new bands appear at 1034 and $1014 \mathrm{~cm}^{-1}$ in the $\left[\mathrm{FePc}\left\{\mathrm{P}(\mathrm{OMe})_{3}\right\}_{2}\right]$ spectrum. By analogy with the organic compounds of phosphorus [20], they can be attributed to the vibrations of the axial ligand.

Slight movements of bands between $700-800 \mathrm{~cm}^{-1}$ can be observed (see Table 3 ). This region, which shows the $\mathrm{C}-\mathrm{H}$ out of plan vibrations, is sensitive to the modifications of the crystalline structure. Therefore, it is not unexpected that the bands of this region are perturbed by the axial ligand fixation. A new band ascribable to the distortion of the $\mathrm{P}-\mathrm{Ph}$ link [20] appears at 700,714 and $703 \mathrm{~cm}^{-1}$, respectively, in the $\left[\mathrm{FePc}\left\{\mathrm{PPh}_{3}\right\}_{2}\right],\left[\mathrm{FePc}\left\{\mathrm{PPh}_{3}\right\}\right]$ and $\left[\mathrm{FePc}\left\{\mathrm{PPh}(\mathrm{OMe})_{2}\right\}\right]$ spectra. The presence of the bands of the vibrations ascribable to the axial ligands confirm the formation of these compounds.

Table 3. IR bands noticeable between 700 and $800 \mathrm{~cm}^{-1}$.

\begin{tabular}{|c|c|c|c|c|c|c|c|c|c|}
\cline { 2 - 10 } \multicolumn{1}{c|}{} & \multicolumn{5}{c|}{$\left[\mathrm{FePc}\left\{\mathrm{PX}_{3}\right\}_{2}\right]$} & \multicolumn{4}{c|}{$\left.\left[\mathrm{FePc}\{\mathrm{PX}\}_{3}\right\}\right]$} \\
\hline $\mathrm{FePc}$ & $\mathrm{PMe}_{3}$ & $\mathrm{P}(\mathrm{OMe})_{3}$ & $\mathrm{PPh}_{3}$ & $\mathrm{P}(\mathrm{OPh})_{3}$ & $\mathrm{POH}(\mathrm{OEt})_{2}$ & $\mathrm{PPh}_{3}$ & $\mathrm{P}(\mathrm{OPh})_{3}$ & $\mathrm{PPh}(\mathrm{Ome})_{2}$ & $\mathrm{POH}(\mathrm{OEt})_{2}$ \\
\hline- & - & 797 & 775 & - & - & 790 & - & - & 796 \\
\hline 770 & 777 & 775 & 770 & 772 & 778 & 780 & 783 & 774 & 780 \\
\hline 748 & 752 & 757 & 750 & 748 & 752 & 750 & 753 & 752 & 750 \\
\hline 724 & 728 & 740 & 730 & 724 & 728 & 728 & 734 & 728 & 730 \\
\hline & & & 700 & - & - & 714 & - & 703 & - \\
\hline
\end{tabular}

The $200-650 \mathrm{~cm}^{-1}$ domain is very sensitive to the symmetry around the central metal and to its formal state of oxidation [21]; it is therefore expected that phosphine and phosphite ligation fixation will result in modifications in the FePc spectrum.

We were particularly interested in the evolution of the $v_{\mathrm{FeN} 4}$ band [22] which is shown at 308 $\mathrm{cm}^{-1}$ in the FePc spectrum (see Table 4).

Table 4. Frequency of the $v_{\mathrm{FeN} 4}\left(\mathrm{~cm}^{-1}\right)$ band.

\begin{tabular}{|c|c|c|c|c|c|c|c|c|}
\cline { 2 - 9 } \multicolumn{1}{c|}{} & \multicolumn{4}{c|}{$\left[\mathrm{FePc}\left\{\mathrm{PX}_{3}\right\}_{2}\right]$} & \multicolumn{3}{c|}{$\left[\mathrm{FePc}\left\{\mathrm{PX}_{3}\right\}\right]$} \\
\hline $\mathrm{FePc}$ & $\mathrm{PMe}_{3}$ & $\mathrm{P}(\mathrm{OMe})_{3}$ & $\mathrm{PPh}_{3}$ & $\mathrm{P}(\mathrm{OPh})_{3}$ & $\mathrm{POH}(\mathrm{OEt})_{2}$ & $\mathrm{PPh}_{3}$ & $\mathrm{P}(\mathrm{OPh})_{3}$ & $\mathrm{POH}(\mathrm{OEt})_{2}$ \\
\hline 308 & 328 & 320 & 337 & 330 & 330 & 310 & 308 & 308 \\
\hline
\end{tabular}

In the spectra of the pentacoordinated species the frequency of the $v_{\mathrm{FeN} 4}$ band does not show much variation; such a phenomenon has already been observed with thiolate complexes of FePc 
[17]. On the other hand, in the spectra of the hexacoordinated derivatives, the $v_{\mathrm{FeN} 4}$ band moves towards high frequencies (see Table 4).

Some authors have already suggested that the shift of this band towards high frequencies in the spectra of certain $\mathrm{FePcL}_{2}$ complexes is closely related to the donating power of the axial ligand [8]. In the case when $\mathrm{L}$ is pyridine or a substituted pyridine, shift is greater the stronger the donor properties of the ligand. In our study, we could not show any correlation between the donating power of the axial ligand and the value of the $v_{\mathrm{FeN} 4}$ movement. However, as in the case when the ligand is a nitrogen aromatic base, we can assume that in the ligand series we have used, the donating power remains predominant.

\section{CONCLUSION}

In this work, we have prepared and isolated in a solid form the following complexes: $\left[\mathrm{FePc}\left\{\mathrm{PMe}_{3}\right\}_{2}\right],\left[\mathrm{FePc}\left\{\mathrm{P}(\mathrm{OMe})_{3}\right\}_{2}\right],\left[\mathrm{FePc}\left\{\mathrm{PPh}_{3}\right\}_{2}\right],\left[\mathrm{FePc}\left\{\mathrm{P}(\mathrm{OPh})_{3}\right\}_{2}\right], \quad\left[\mathrm{FePc}\left\{\mathrm{POH}(\mathrm{OEt})_{2}\right\}_{2}\right]$, $\left[\mathrm{FePc}\left\{\mathrm{PPh}_{3}\right\}\right],\left[\mathrm{FePc}\left\{\mathrm{P}(\mathrm{OPh})_{3}\right\}\right],\left[\mathrm{FePc}\left\{\mathrm{POH}(\mathrm{OEt})_{2}\right\}\right]$ and $\left[\mathrm{FePc}\left\{\mathrm{PPh}(\mathrm{OMe})_{2}\right\}\right]$.

For $\mathrm{PPh}_{3}, \mathrm{P}(\mathrm{OPh})_{3}$ and $\mathrm{POH}(\mathrm{OEt})_{2}$, the nature of reaction product depends on the quantity of ligand used. For FePc:L 1:1, the compound obtained is pentacoordinated and for in FePc:L 1:2 ratio a hexacoordinated complex is obtained.

In electronic spectrometry we have observed charge transfer transitions at $375 \mathrm{~nm}$ and 421 $\mathrm{nm}$. That at $375 \mathrm{~nm}$ is attributable to an axial ligand charge-transfer $\rightarrow$ macrocycle and that at $421 \mathrm{~nm}$ represents a metal charge transfer $\rightarrow$ axial ligand.

Vibrational spectrometry has made it possible for us to show that in the hexacoordinated complexes, the $\mathrm{v}_{\mathrm{FeN} 4}$ frequency moves towards high values while in the pentacoordinated derivatives, its frequency remains almost constant.

\section{REFERENCES}

1. Schramn, C.J.; Scarings, R.P.; Stojakovic, D.R.; Hoffman, B.M.; Ibers, J.A.; Marks, J.T. J. Am. Chem. Soc. 1980, 102, 6702.

2. Hurray, R.W. Electroanalytical Chemistry, Bard, A.J. (Ed.); Marcel Dekker: New York; 1984.

3. Ley, M. Doctorat d'Université The $\nabla e$, University of Aix en Provence, Marseille, France, 1989.

4. Berezin, B.D. Coordination Compounds of Porphyrins and Phthalocyanins, Nauka: Moscow; 1978.

5. Hanack, M.; Seeling F.F.; Streihle J. Naturforsh Z., Teil A 1979, 34, 983.

6. Philipps, T.E.; Scarings, R.P.; Hoffman, B.M.; Ibers J.A. J. Am. Chem. Soc. 1980, 102, 3436.

7. Hemptead, M.R.; Lever, A.B.P.; Leznoff, C.C. J. Electroanal. Chem. 1987, 65, 2677.

8. Ouédraogo, G.V.; More, C.; Richard, Y.; Benlian, D. Inorg. Chem. 1981, 20, 4347.

9. Bayo, K.; Saba, A.; Ouédraogo, G.V.; Benlian, D. J. Mol. Struct. 1992, 271, 19.

10. Bayo, K.; Ouédraogo, G.V.; Terzian, G.; Benlian, D. Polyhedron 1990, 9, 1087.

11. Ouédraogo, G.V.; Porte, L.; Benlian, D. J. Chem. Phys. 1980, 73, 642.

12. Wayland, B.B.; Abd El-Mageed, M.F.E. J. Am. Chem. Soc. 1974, 96, 4809.

13. Sweigart, D.A. J. Chem. Soc. Dalton 1976, 1476.

14. Taube, R. Pure Appl. Chem. 1974, 38, 427.

15. Ouédraogo, G.V.; Mossoyan-Deneux, M.; Benlian, D. C.R. Acad. Sci., Paris 1978, $286,517$.

16. Ouédraogo, G.V. The Ve d'Etat, University of Aix en Provence, Marseille, France, 1977. 
17. Bangoura, M. Doctorat de Spécialité The $\nabla e$, University of Ouagadougou, Burkina Faso, 1997.

18. Stymne, B.; Sauvage, F.X.; Wetter Mark, G. Spectrochim. Acta 1979, 35A, 1195.

19. Henderson, Jr., W.A.; Streuli, C.A. J. Am. Chem. Soc. 1960, 82, 5791.

20. Socrate, C. Infrared Characteristic Groups Frequencies, 2nd ed., Wiley Interscience: New York; 1980.

21. Terzian, G.; Moubaraki, B.; Mossoyan, M.-Deneux; Benlian, D. Spectrochim. Acta 1989, $45 \mathrm{~A}, 675$.

22. Kobayashi, T. Spectrochim. Acta 1970, 26A, 1313. 